\title{
CORRECTION
}

\section{Correction to: The impact of different doses of indocyanine green on the sentinel lymph-node mapping in early stage endometrial cancer}

\author{
Andrea Papadia ${ }^{1}$ - Alessandro Buda ${ }^{2} \cdot$ Maria Luisa Gasparri ${ }^{1} \cdot$ Giampaolo Di Martino $^{2} \cdot$ Beatrice Bussi $^{2}$. \\ Debora Verri ${ }^{2} \cdot$ Michael D. Mueller $^{1}$
}

Published online: 8 September 2018

(c) Springer-Verlag GmbH Germany, part of Springer Nature 2018

\section{Correction to: Journal of Cancer Research and Clinical Oncology https://doi.org/10.1007/s00432-018-2716-3}

Unfortunately, the $P$ value at multivariate analysis for ICG concentration in Table 3 was incorrectly published. The correct value is 0.084 . The corresponding OR value is also corrected in the below table (Table 3 ).
Table 3 Univariate and Multivariate analysis factors associated with Bilateral Detection rate (All patients, $n$ $=168$ )

\begin{tabular}{|c|c|c|c|c|}
\hline & \multicolumn{4}{|c|}{ Bilateral detection (yes/no) } \\
\hline & \multicolumn{2}{|l|}{ Univariate analysis } & \multicolumn{2}{|c|}{ Multivariate analysis } \\
\hline & OR $(95 \% \mathrm{CI})$ & $p$ & OR $(95 \% \mathrm{CI})$ & $p$ \\
\hline Age $(<64$ vs $\geq 64)$ & $1.37(0.54,3.45)$ & 0.49 & & \\
\hline BMI $(\geq 35$ vs $<35)$ & $0.44(0.15,1.29)$ & 0.13 & $0.34(0.11,1.07)$ & 0.066 \\
\hline Tumor volume $(\geq 2 \mathrm{vs}<2 \mathrm{~cm})$ & $1.34(0.54,3.33)$ & 0.52 & & \\
\hline LVSI (positive vs negative) & $0.73(0.15,3.45)$ & 0.69 & & \\
\hline ICG concentration ( 5 vs $1.25 \mathrm{mg} / \mathrm{ml}$ ) & $2.2(0.88,5.52)$ & 0.09 & $2.64(0.81,6.92)$ & 0.084 \\
\hline
\end{tabular}

Multivariable models were carried out for variables reporting a $p$ value $\leq 0.25$ in the univariate analysis

The original article can be found online at https://doi.org/10.1007/ s00432-018-2716-3.

\footnotetext{
Andrea Papadia andrea.papadia@insel.ch

1 Department of Obstetrics and Gynecology, University Hospital of Bern, University of Bern, Effingerstrasse 102, 3010 Bern, Switzerland

2 Unit of Gynecologic Oncology Surgery, Department of Obstetrics and Gynecology, San Gerardo Hospital, University of Milano-Bicocca, Monza, Italy
} 